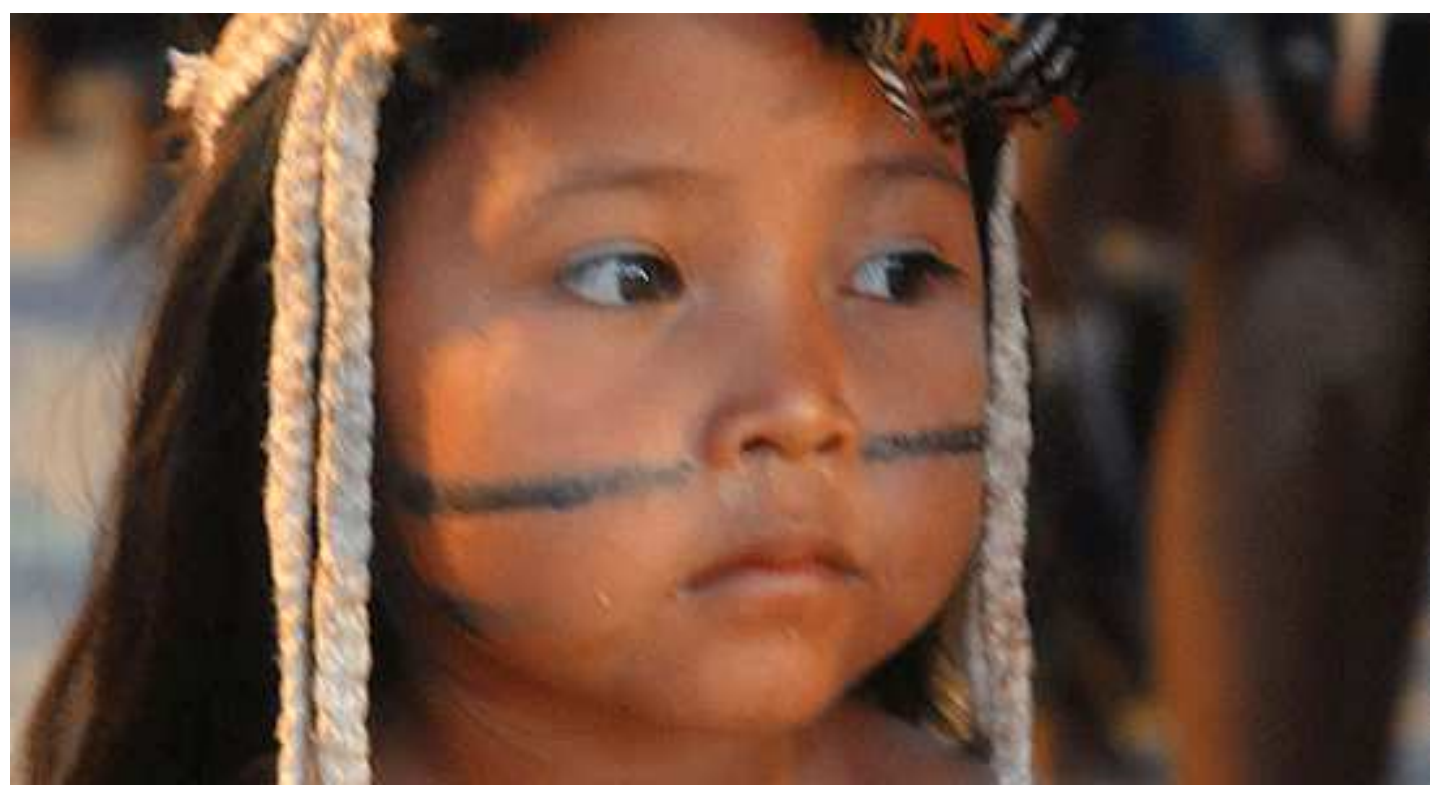

\title{
Subjetividade e discurso: a representação da língua (indígena e portuguesa) para professores Terena
}

Subjectivity and discourse: the representation of language (Indian and Portuguese) to Terena teacher

\author{
Alessandra Manoel Porto* \\ Vânia Maria Lescano Guerra**
}

Resumo: Este trabalho propõe analisar as representações de língua e linguagem no discurso de professores Terena, da Região Aquidauana (MS), enquanto mecanismos de controle e de defesa de uma etnia parcialmente bilíngue frente à sociedade hegemônica. Os procedimentos teóricos e metodológicos recorrem ao método genealógico foucaultiano (1987, 1990, 1992, 1997), às noções de identidade e subjetividade abordadas por Bauman (2005) e Guerra (2010) e às questões de língua discutidas por Cavalcanti e César (2007) e Coracini (2003, 2007), numa visão transdisciplinar permeada pelas relações de poder.

Palavras-chave: Língua; professor indígena, discurso, subjetividade.

Abstract: This study proposes to analyze the representations of language and language in discourse of the Terena teachers, Region Aquidauana (MS), while control mechanisms and defense of an ethnic partially bilingual front hegemonic society. The theoretical and methodological procedures use the Foucauldian genealogical method $(1987,1990,1992,1997)$, the notions of identity and subjectivity addressed by Bauman (2005) and Guerra (2010) and questions of language discussed by Cavalcanti and Cesar (2007) and Coracini $(2003,2007)$, in a transdisciplinary vision permeated by power relations.

Keywords: Language, indian teacher, discourse, subjectivity

\footnotetext{
Mestre em Letras na área de Estudos Linguísticos, do Programa de Mestrado em Letras da UFMS, Campus de Três Lagoas (MS). End: Av. Capitão Olintho Mancini 1662 - Jardim Primaveril Universidade Federal de Mato Grosso do Sul - Programa de Mestrado em Letras - Três Lagoas (MS) CEP 79603-011. Email: alemporto@yahoo.com.br

Docente na graduação e na pós-graduação em Letras, da Universidade Federal de Mato Grosso do Sul (UFMS), Campus de Três Lagoas (MS) End.: Av. Capitão Olintho Mancini 1662 - Jardim Primaveril Universidade Federal de Mato Grosso do Sul - Programa de Mestrado em Letras - Três Lagoas (MS) CEP 79603-011 Email: vguerra1 @ terra.com.br.
} 


\section{Considerações Iniciais}

Temos por objetivo problematizar o processo de construção da identidade dos docentes da etnia Terena, com formação superior oferecida pela sociedade dominante, mas que "resguardam" a identidade étnica. A fundamentação teórica transdisciplinar desta pesquisa, a partir das perspectivas discursiva e culturalista, trazem estudos de Coracini (2003, 2007), Eckert-Hoff (2008), Foucault (1990, 1992), Bauman (2010), entre outros.

Para melhor entendimento das condições de produção dos discursos ora analisados, retomemos o período da história da colonização do Brasil pelos portugueses: a língua portuguesa foi "imposta" aos índios como premissa da catequização, no entanto, conforme Orlandi (2002), a ideologia implícita na ação de catequizar era a da implantação do Estado Nacional, da língua oficial, por Portugal, no século XVI.

A etnia Terena, que hoje vive na Região Aquidauana, em Mato Grosso do Sul, tem origem no grupo Aruák (família linguística), vindo do Chaco Paraguaio, que se subdividiu em outros subgrupos (Guaná e Txané), dos quais temos o povo Terena que se instalou no centro-oeste do estado (OLIVEIRA, 1976). Atualmente, o povo Terena passa por mudanças significantes na educação, uma vez que, no Brasil, do século XVI até praticamente metade do século XX, a educação escolar indígena esteve pautada pela catequização, pela civilização e pela inserção forçada dos índios à sociedade nacional: sempre negando a diferença e, assim, tornando-os "brasileiros", obrigava-os a refutar a sua identidade étnica. Somente em anos recentes esse quadro começou a mudar e pôde contar com várias experiências nas diversas regiões do Brasil, constituindo projetos educacionais adequados à realidade sociocultural dos grupos indígenas por meio dos estudos da interculturalidade e do bilinguismo, fundamentados no Parecer 14/99. (BRASIL, 1999).

Como ponto de equilíbrio, o ensino bilíngue, no contexto indígena, situa-se entre os valores culturais representados pela língua materna e os saberes universais veiculados pela língua nacional. Há que se atentar, no entanto, para uma situação de bilinguismo real e para a tentativa de implementá-la, pois, na maioria das escolas em que os sujeitos entrevistados atuam, dentre elas Cachoeirinha, Lagoinha e Água Branca, as comunidade são falantes e o ensino pode ser considerado bilíngue, porque tanto os professores quanto os alunos são bilíngues (utilizam as duas línguas, a Terena e a Portuguesa) em sala de aula, nas diversas disciplinas e fora da escola também. Já nas 
demais escolas (Lalima, Limão Verde e Aldeinha), o que de fato existe, na "grade curricular", são as disciplinas Língua Terena e Língua Portuguesa. Nesse caso, há o ensino da língua materna (Terena), mas as relações de ensino se dão em língua portuguesa, embora os sujeitos entrevistados nesta pesquisa, com exceção de apenas um deles, sejam bilíngues.

É a partir do contexto histórico em que a comunidade Terena está situada implantação e reestruturação de escolas indígenas nas aldeias, formação superior de professores indígenas (além de pós-graduação) e projetos de fortalecimento da língua materna - que se esteia a nossa pesquisa.

É na esteira da discussão apontada que buscamos, preliminarmente, em estudos de Coracini (2003), a noção de língua materna e a sua relação com outra no caso do bilinguismo:

Língua materna significa etimologicamente língua da mãe, ensinada pela mãe [...]. Na escola, tem-se assumido como língua materna aquela em que a criança foi alfabetizada, língua que coincide, em muitos casos, embora nem sempre, com o registro oficial - padrão - do país em questão; outras vezes, com a língua nacional, sem levar em conta a primeira língua em que a criança aprendeu a falar. [...] "Língua materna" indica também a primeira língua adquirida, mas há casos - e são inúmeros - em que a criança aprende duas ao mesmo tempo (situações de bilinguismo). (CORACINI, 2003, p. 145).

O fato que nos chama a atenção é que, no caso dos Terena, a situação bilíngue instaurada não permite que se distinga a língua materna da língua estrangeira, porque, dentre as aldeias pesquisadas da Região Aquidauana, não há comunidade que só fale em Terena, mesmo que a considere como língua materna e não conceba a língua portuguesa como língua estrangeira. Embora não seja nosso objetivo levantar dados que propiciem ou não a vitalidade da língua Terena, para que compreendamos melhor a problemática da L1 e da L2 e o lugar que elas ocupam, é relevante citarmos o caso de duas aldeias que se distanciam por quatro quilômetros, mas, em uma delas, a Bananal, a comunidade é realmente bilíngue. Nela, a L1 é utilizada nas reuniões religiosas, de lutas pela terra, no convívio familiar e na escola; já na aldeia Ipegue, a L2 é a língua materna, e o Terena passa a ser apenas substrato linguístico, pois foi "substituído" em favor da língua nacional, restando somente vestígios desta.

Ressaltamos ainda que os Terena, além de pertencerem a um grupo culturalmente distinto do branco, diferem de outros grupos étnicos também. Eles são constituídos por particularidades das quais destacamos a estratégia de mobilidade político-linguística, isto é, as duas línguas são sinônimos de poder. Assim, a resistência 
pela sobrevivência da língua Terena vem sendo articulada e representada, pelos indígenas, por meio de estratégias variadas ao longo da história e conforme as políticas da sociedade hegemônica.

É característica dos Terena, conforme asseveram Ladeira e Azanha (2004), a mobilidade, traço que favorece os estereótipos sociais, "tais como 'aculturados' e 'índios urbanos"', mas que reafirmam a resistência de um povo-minoria em relação ao poder da sociedade majoritária. Podemos afirmar, de acordo com relatos orais ${ }^{1}$, que tais traços constituintes da identidade do povo Terena impulsionam sua inserção no mundo dos brancos e a luta pelo seu espaço, podendo ser caracterizado, por esses aspectos, como um povo expansionista.

A análise dos dados pauta-se na metodologia foucaultiana (1990; 1992), a partir dos pressupostos teóricos da arqueologia discursiva e da genealogia do poder. O corpus deste estudo é constituído de entrevistas com professores indígenas, todos com formação superior (Normal Superior Indígena), realizada in locu ( em aldeais da região Aquidauana - MS), utilizando-se de recursos midiáticos (gravador, notebook e microfone) para coleta dos dados, além de um questionário pré-organizado, com questões que abordavam o tema em pauta. A transcrição dos dados (sequências discursivas) foi realizada por nós e procurou ser o mais fiel possível aos alongamentos, à altura da voz e às ênfases, fatores significativos nesse gênero textual. Assim foram representados: letras maiúsculas, ou seja, caixa alta (tom enfático), reticências (pausa simples) e dois pontos (pausa alongada), com base nos estudos de PRETI (2001).

Esclarecemos, ainda, que, ao nos referirmos à língua Terena, designamo-la como L1; à língua Portuguesa, coube a designação L2. Esse modo de referência foi selecionado para que se evitem ambiguidades nas questões de língua materna e língua estrangeira, uma vez que as condições de produção alertam-nos para a possível problemática.

Nesse cenário de "disputa" e "escolhas", instaura-se mais uma vez a batalha política linguística dos Terena, povo constituído por grande poder de mobilidade (talvez o ethos dessa etnia) em pleno século XXI, com indígenas de ambos os sexos, em busca por formação superior, particularmente na área de Educação e, ainda, por iniciativas de projetos para fortalecimento da língua terena, é que delineamos nosso estudo.

\footnotetext{
${ }^{1}$ Entrevistas realizadas com um grupo de professores Terena no período de 24 a 26-08-2010, cujos recortes de enunciados compõem parte do corpus desta pesquisa.
} 


\section{As questões da língua e da linguagem e seus fundamentos}

As questões de língua, a partir dos estudos iniciados no século XVI, com o advento da gramática de Port-Royal, segundo Cardoso (1999), passaram a ser decisivas para se compreender a estrutura e o funcionamento da língua e suas inúmeras possibilidades de uso, concebida, a partir de então, para além se sua estruturação linguística, com estrutura finita, mas como algo necessário, com função e condição de comunicação, em uso na interação dos indivíduos com o mundo e com a cultura. A carga ideológica que constitui uma língua leva, simultaneamente, a representá-la como instrumento de poder. Assim, a característica da língua como um simulacro de unidade remete-nos para um viés de desconstrução da língua como pura e única.

Nessa perspectiva, é pertinente trazermos para a discussão o conceito de "mito do monolinguismo" discutido por Cavalcanti e César (2007), que corroboram a relevância do tema em se tratando de línguas minoritárias (a exemplo da Terena) e língua nacional (Portuguesa). Para as autoras, tal advento ignora as línguas nacionais minoritárias (línguas indígenas, dialetos de imigrantes, Libras, entre outras) em favor da língua nacional, como se todos os habitantes da nação falassem uma única língua, a dita oficial.

São configurações apresentadas semelhantes a essas que validam a afirmação de Mariani (2004, p. 27), de que caem por terra os discursos que "configura[m] o imaginário de uma unidade e de uma homogeneidade garantidora da intersubjetividade social e geográfica".

Ao instaurar as discussões sobre a língua, trazemos também a concepção de língua de Bakhtin (2006), como uma entidade viva e signo ideológico-social, constitutiva da interação entre os sujeitos e utilizada como meio de reflexão nas diversas realidades. Como um fato social, ela existe porque há necessidade de interação, e é nesse vácuo que surge a linguagem como condição enunciativa, que cria todo o processo de interação verbal. Conforme Bakhtin (2006), a linguagem está intrinsicamente ligada ao enunciado, como ato histórico e irrepetível; e é assim que se manifestam a língua e a linguagem no discurso, como interação dos envolvidos, como reveladora de toda a carga ideológica contida na produção discursiva, pois, em cada 
ação "linguageira", as expressões adquirem sentidos distintos, marcadas pelos movimentos constitutivos da história dos sujeitos.

No entanto, quando falamos de língua, não se trata somente da utilização desta na sua materialidade, nem tampouco só da linguagem, como língua em movimento; o discurso constitui um cenário em que estão envolvidos a língua, o sujeito e o espaço histórico cultural e social. Desse depreendimento, segundo Coracini (2007), é que a Análise do Discurso de linha francesa (AD) evoca três áreas do conhecimento: a Linguística, o Materialismo Histórico e a Psicanálise, que, articulados, têm como premissa os processos discursivos e suas relações ideológicas, ligados às relações de poder imbricados na/além da sua materialidade.

Pela sua estrutura material, a língua é capaz de produzir "verdades" e registrálas, fazer-se compreender sob os múltiplos papéis sociais e ideológicos que ocupa. Daí as palavras de Foucault sobre a escrita como testemunha, pois, para o filósofo, ela "constitui uma prova e como que uma pedra de toque: ao trazer à luz os movimentos do pensamento, dissipa a sombra interior onde se tecem as tramas do inimigo" (FOUCAULT, 1992, p. 131).

Nessa direção, afirmamos, com Foucault (1987, p. 56), que o discurso não pode mais ser concebido como conjunto de signos, mas como uma prática que envolve outros objetos; em especial, como instância histórica e social. O discurso é a junção de saberes, organizando-se como práticas discursivas que revelam, por meio de escolhas lexicais, qual relevância ou qual silenciamento discursivo deve ser dispensado a determinados acontecimentos, à medida que o próprio sujeito assume uma posição discursiva. É desse emaranhado que surge o conceito de formação discursiva. Assim,

sempre que se puder descrever, entre um certo número de enunciados, semelhante sistema de dispersão e se puder definir uma regularidade (uma ordem, correlações, posições, funcionamentos, transformações) entre os objetos, os tipos de enunciação, os conceitos, as escolhas temáticas, teremos uma formação discursiva (FOUCAULT, 1987, p. 43).

Por meio do discurso, nessa perspectiva, o sujeito (inserido/parte da história) despe-se e desnuda suas identidades, mesmo que inconscientemente. Na concepção (pós)moderna, não há mais uma identidade fixa, essencial ou permanente. A esse respeito, Coracini (2007) afirma que a identidade torna-se uma "celebração móvel", mesmo que o sujeito prime pela (in)alteração de valores, porque tem a ilusão de que é um sujeito com identidade definida, acabada. Há um esfacelamento daquela identidade definida porque a própria necessidade de interação social exige ou o momento histórico 
requer -, no entanto os conflitos surgem porque nem sempre a representação ostentada coincide com aquela que o sujeito gostaria de ter ou de "representar".

Bauman (2005, p. 38) assevera que a identidade do indivíduo moderno passa por um enfrentamento, que ele denomina ambivalência das identidades, "bênçãos ambíguas", pois estas "oscilam entre o sonho e o pesadelo, e não há como dizer quando um se transforma no outro". Essa concepção instiga-nos a trazer em pauta os estudos de Guerra (2010, p. 72) sobre o indígena sul-mato-grossense, como sujeito que se encontra num "entre-lugar identitário, nesse entre-espaço cultural e histórico: nem branco, nem bugre". Esse sujeito, diante das complexidades sociais, das pressões da sociedade hegemônica, mas também como sujeito do desejo do outro, são sujeitos sucumbidos, segundo a teoria do mito Narciso-Vampiro, introduzida por Eckert-Hoff (2008):

Narciso é símbolo da atitude autocontemplativa, introvertida e a absoluta que aflige o sujeito [...] é a incapacidade de reconhecer o outro, alerta para a ilusão da inteireza, para a fascinação do eu que se afoga em si-mesmo-noOutro. O mito do Vampiro [...] é a incapacidade de reconhecer a morte: a morte é, ela mesma, a ausência de significado, a impossibilidade de simbolização. (ECKERT-HOFF, 2008, p. 68)

O duplo Narciso-Vampiro representa a dualidade vivida pelo sujeito, ora como desejo de mostrar-se ao outro, ora como receio de não ser visto. Esse posicionamento de se mostrar e de se esconder remete-nos à metáfora do camaleão, também discutida por Eckert-Hoff (2008), cujo aspecto da alteração das cores nada mais é que uma camuflagem de proteção contra o inimigo, ou seja, de uma ação ideologicamente engendrada de retaguarda - às vezes deixa de ser um (índio/L1) para ser outro (branco/L2) e vice-versa.

A dualidade, acentuada pela política linguística dos Terena, ancora-se nos reflexos do bilinguismo diglóssico e compulsório estudado por Nincao (2008), a partir da teoria de Ferguson: o fenômeno ocorre numa situação em que há, no cenário, duas línguas, sendo uma minoritária e outra majoritária. Podemos asseverar que tal ocorrência instiga o sujeito à escolha de uma língua ao invés da outra e que as causas fundantes dessa escolha não são aleatórias; elas se ancoram nas relações de poder construídas ao longo da história, tanto pelas ideologias da sociedade dominante (com ênfase no poder público), como também nas estratégias ideológicas de sobrevivência das comunidades étnicas, que nem sempre são respeitadas quando optam por fazer uso da língua portuguesa (MAHER, 2006). A “escolha” da L2 ao invés da L1 no início dos aldeamentos instiga o indígena do século XXI a rever a opção, em virtude do 
espelhamento da sociedade - o índio "verdadeiro" fala a língua indígena. Como a língua, nesse espaço, "ganha" outra concepção, avaliamos, pelas palavras de Foucault (1992, p. 142), que "o contraste desejado não exclui a unificação". Assim, recorremos ao postulado do autor para compreender como as relações de força e poder permeiam as discursivizações, que, a partir das regularidades do arquivo, fazem emergir um discurso tenso e contraditório, tal qual assevera Coracini (2007), ora como gozo, ora como estranhamento.

Da perspectiva lacaniana, entendemos "mais gozar" como a condição do sujeito que deseja um "objeto-a-mais", compreendido como causa do desejo e do gozo (cf. ECHERT-HOFF, 2008), aqui problematizado como o desejo de se alcançar um outro mundo, por meio da linguagem, como uma forma de se estar no outro, bem como de sair do "eu". Tal desejo se estabelece por meio da falta, daí a ação de busca. Contudo, trata-se da manifestação inconsciente do querer-saber que gera poder, e necessariamente distinção dentro de um grupo social, bem como a sensação de completude. Dito de outro modo, um sujeito que vê no outro a possibilidade de completude e de gozo.

Vale dizer que todo sujeito se constitui de fragmentos de uma história, de sombras, de acontecimentos, uma descontinuidade, uma história de vida, em que o sujeito se reencontra e se perde. Assim, a análise de um campo discursivo busca compreender o enunciado em sua singularidade de acontecimento (FOUCAULT, 1987, p. 31), procurando elucidar as condições de sua emergência e estabelecendo relações com outros discursos. Para o autor, um enunciado é sempre acontecimento, uma vez que abre espaço para sua inscrição na memória já que é suscetível de repetição, transformação e reativação, sobretudo porque está ligado ao interdiscurso, ou seja, a outros enunciados que vieram antes e depois dele ou, no dizer de Orlandi: "aquilo que fala antes, em outro lugar, independentemente" (2009, p. 30). Ligada à memória discursiva encontra-se a noção de arquivo, aqui abordado pelas lentes foucaultianas como aquilo que:

\footnotetext{
faz com que tantas coisas ditas por tantos homens, há tantos milênios, não tenham surgido apenas segundo as leis do pensamento, ou apenas segundo o jogo das circunstâncias, que não sejam simplesmente a sinalização, no nível das performances verbais, do que se pôde desenrolar na ordem do espírito ou na ordem das coisas (FOUCAULT, 1987, p. 146).
}

$\mathrm{Na}$ atualidade, há toda uma discursividade no que se refere à identidade cultural, questão esta firmemente debatida na teoria social, sobretudo no que diz respeito à constituição das identidades étnicas, de minorias ou grupos marginalizados. Falar sobre 
sujeito na (pós)modernidade é abordar um tema complexo e até mesmo polêmico. Isso porque nós, ocidentais, vivemos em uma cultura baseada ainda em binarismos antagônicos em que cada ser ou objeto se distingue dos demais, a priori, pela diferenciação (bom/mau, homem/mulher, certo/errado, etc.). Nessa perspectiva, EckertHoff (2008) pontua:

Falar em pós modernidade, portanto, implica designar algo que não é fixo e não pode ser sistematizado, já que não se trata de uma filiação a um modelo acabado e fechado; trata-se sempre e inevitavelmente, de uma contradição, uma descontinuidade, um curto-circuito de sentidos, o que implica um deslocamento com relação a racionalidade da ciência moderna e com relação às verdades instauradas na cultura ocidental. (ECKERT-HOFF 2008, p. 39)

Contudo, os processos de identificação não são construídos a partir da anulação de uma identidade em detrimento a outra, mas pela imbricação de imagens identitárias que se mesclam formando e (de)formando o sujeito, via o inconsciente, daí a impossibilidade se ser o que se deseja, ou de se mostrar como se quer ser visto. Dessa forma, além de perscrutar caminhos que envolvem questões históricas e culturais, a análise de discursos realizada neste trabalho mostra também a seleção de vocábulos e de determinadas expressões e construções sintáticas dentro dos excertos a serem analisados, posto que a materialidade linguística de tais enunciados constitui relevante "pista" que levará ao objetivo proposto.

\section{A representação da língua (Terena e Portuguesa) como mecanismo de controle pelos sujeitos}

Trazemos para esta discussão, apenas dois excertos transcritos por nós, parte dos dados coletados na entrevista com professores Terena, integrante da dissertação de mestrado intitulada "Um olhar discursivo para as representações de língua e linguagem de professores Terena", defendida no Programa de Mestrado em Letras da Universidade Federal de Mato Grosso do Sul (UFMS). Os recortes remetem ao discurso de dois professores graduados em Normal Superior Indígena (o primeiro deles, pós-graduado em Ciências Sociais), falantes da língua Terena, e tanto os professores como as sequências discursivas a serem apresentadas foram selecionados dentre o corpus (entrevista transcrita), por atenderem aos objetivos deste trabalho. Os recortes foram organizados em SP1 e SP2.

Inicialmente, apresentamos o discurso de SP1, que, via memória discursiva, a partir do questionamento "Professor, como você vê a relação dos Terena com a língua 
materna (L1) e a língua portuguesa (L2)?”, faz menção à escolha da L2 pelos antepassados, refutando a L1 por temor quanto ao futuro da etnia. Tanto em relação ao passado como ao presente, a L2 é, no entanto, concebida em seu discurso como recurso estratégico de controle (defesa e sobrevivência) para o enfrentamento da sociedade dominante, a saber:

SP1- [...] a língua portuguesa... primeiro pra defesa... segundo pro próprio comunicação... com o mundo do branco... né:... [...] defesa no sentido assim... ah: se... se eu não sei nenhuma língua... como... não falo... nem entendo a língua portuguesa como é que eu vou comunicar com você... que eu vou me defender... [...] ...e até mesmo de defesa atualmente hoje... serve sim... a língua é importante porque por exemplo se nós tamo num mundo... a:... branco... [...]:... então nessa preocupação os pais também já... começaram em casa falar um pouco da língua portuguesa pra quando eles chegar na escola eles não tenha uma grande dificuldade como os pais passaram... para exatamente... questão profissional... questão de integração... questão de relacionamento com outras pessoas que não seja Terena... então: é isso é... fundamental... na época foi uma perda para nós... mas foi uma estratégia... digamos assim... de sobrevivência do povo Terena.

Podemos constatar, no discurso de SP1, a referência à L2 como meio estratégico dos Terena para ter acesso ao "mundo do branco". O discurso é marcado, ideologicamente, a partir da materialidade linguística - defesa, defender, questão profissional, questão de integração, questão de relacionamento, estratégia, perda e sobrevivência -, pelo discurso de guerra ou batalha, em que se trava uma luta contra um inimigo. Por meio da escolha lexical, analisamos o teor do discurso de SP1: como a L1 é considerada característica primeira para demarcar a identidade indígena, a L2 configura-se como "ameaça", representando o branco e, assim, aprendê-la ou refutá-la provoca um conflito identitário interior; daí todo o discurso ser permeado por escolhas lexicais que nos remetem a um discurso de combate.

A sequência discursiva surge como uma marca de tensão, característica das práticas discursivas, pois a defesa proposta pelo sujeito é algo ameaçador, mas que deve ser enfrentado; caso contrário, haveria consequências maiores. Desse modo, compreendemos, à luz das ponderações de Foucault (1990), que o discurso não é neutro; ele ganha força no centro de uma prática discursiva com o objetivo de fomentar a verdade. A "batalha", referendada pelo sujeito, é enunciada, via memória discursiva, materializada pelos itens lexicais na época e atualmente hoje. Embora SP1, nesse excerto, não relate os acontecimentos que o fazem dividir seu discurso, na linha do tempo, em dois marcadores temporais distintos, depreende-se que ele afirma ser uma estratégia utilizada pelo povo Terena em relação ao fato de a língua ser falada numa 
situação de mobilidade, tanto no passado como no presente: defesa e sobrevivência da etnia, já que as relações com a sociedade dominante não poderiam ser mais evitadas.

Em outras palavras, há a instauração de relações de poder ao ser aceita essa condição de mobilidade pelos Terena, como assevera Foucault (1997, p. 241): “a partir do momento em que há uma relação de poder, há uma possibilidade de resistência. Jamais somos aprisionados pelo poder: podemos sempre modificar sua dominação em condições determinadas e segundo uma estratégia precisa". Para SP1, a escolha da L2 nos dois momentos não significa refutar a L1, mas sim, (res)significa numa estratégia de controle para garantir que consigam permanecer índios (NINCAO, 2008).

Para ainda confirmar a relação de poder instaurado, o dizer de SP1, em defesa no sentido assim... ah: se... se eu não sei nem uma língua... como... não falo... nem entendo a língua portuguesa como é que eu vou comunicar com você... que eu vou me defender, traz a representação da L2, pelo sujeito-professor, como elemento essencial para que o branco não "trapaceie" com o índio. Há uma busca, via memória discursiva, do "período de escravidão" citado por Oliveira (1976), em que os Terena, por não terem terra suficiente para o sustento da família, foram levados a trabalhar nas fazendas; como falavam pouco a L2, a comunicação era dificultada e, sem ela, os indígenas eram sempre vítimas de subornos. O vocábulo você remete às vozes do branco: não importando a classe social a que pertença, o branco do ontem e o branco de hoje, ele é uma ameaça que só pode ser neutralizada pela igualdade da língua que se fala: a L2.

Vale problematizar, ainda, as sequências discursivas se eu não sei nenhuma língua e não falo... nem entendo a língua portuguesa, em que SP1 não se refere apenas à L2, mas a qualquer outra língua falada pelo branco. A recorrência da negação, materializada por nenhuma, não, nem, provoca, no discurso, um "despimento" do sujeito, que se apresenta como sinônimo de nada, de ninguém, posição que só é revertida no momento em que fala uma língua que o branco fala, como sentimento de igualdade e de completude. Compreendemos, então, que o imaginário social desse sujeito passa a ser habitado por autorrepresentações tanto positivas quanto negativas em relação ao outro/branco pelo falar da L2, constituindo o que postula Coracini (2003, p. 207): “certamente, por um desejo inconsciente de encontrar um lugar (quase) perfeito, mas também, por experiência dos outros mais do que por sua própria experiência; pela interpretação dos outros, pelas representações veiculadas pela mídia".

A menção à L2 é, no entanto, feita diretamente quando SP1 explicita a estratégia utilizada pelos indígenas no passado quando ela foi sinônimo de minimização dos casos 
de "escravidão", vividos pelos patrícios, o que vem marcar diretamente a conduta dos mais velhos em relação à nova geração: então nessa preocupação os pais também já... começaram em casa falar um pouco da língua portuguesa. Há uma visão de mobilidade na concepção dos pais, como geração mais velha, trazido pelo discurso de SP1, ou seja, se não propiciassem a aprendizagem com a L2, teriam as mesmas dificuldades encontradas pelos pais. A esse respeito, Bauman (2005, p. 57) assevera que "é preciso acreditar que é adequado confiar em escolhas feitas socialmente e que o futuro parece certo". Na assertiva apresentada, fica clara a política linguística articulada pelos Terena de que a aprendizagem da língua do colonizador/branco seria indispensável para a sobrevivência do grupo, como ethos do povo Terena.

Mesmo coadunando-se com a atitude dos antepassados, SP1 não esconde que, embora o evento representasse refutação aos olhos de quem estivesse externo a ele, foi uma conduta sábia dos mais velhos. Em: na época foi uma perda para nós... mas foi uma estratégia, a expressão "perda para nós" pode ser compreendida como um refutação da L1, consideradas as consequências sobre o "hoje" - aqui-agora: nem todos da etnia podem marcar a sua identidade dentro dos princípios eleitos pelos próprios índios, que é serem falantes da L1.

A sobrevivência só é abordada pelo sujeito ao final da sequência discursiva digamos assim... de sobrevivência do povo Terena -, no entanto podemos compreender que, a todo momento em que SP1 usou o vocábulo "defesa", havia uma formação discursiva (FD), ou seja, mecanismos de controle para que houvesse sobrevivência. Mais uma vez, recorremos ao postulado de Foucault (1987, p. 136), que define uma FD como "um conjunto de regras anônimas, históricas, sempre determinadas no tempo e no espaço, que definiram, em uma dada época, e para determinada área, social, econômica, geográfica ou linguística, as condições de exercício da função enunciativa”. Nessa perspectiva, é pertinente incluirmos, nessa discussão, os fundamentos do discurso, na conjuntura do interdiscurso, materializado no intradiscurso por SP1, apontando a L2 como referente, no excerto apresentado, recategorizada por meio de nomes relativos aos processos cognitivos: defesa, comunicar com você, nessa preocupação, questão profissional, questão de integração, questão de relacionamento e isso, que têm como referente a "língua portuguesa". Como não podem ser analisados fora do discurso (porque remetem a suposições e hipóteses discutidas dentro do discurso), fora dele não constituem uma associação semântica, nem tampouco uma repetição. 
Pode-se depreender, a partir das escolhas lexicais propostas por SP1, que os efeitos de sentido estreitam-se para a complexidade e o conflito interior vividos pelo sujeito, pois, nas recategorizações articuladas por ele para se referir à problemática da L1 entre os indígenas, a presença de FDs marca um discurso tenso, em "que o sujeito é sempre constituído por seus duplos: tudo é não-coincidência entre a pessoa e seu nome, entre o eu e o sujeito, entre a língua e sua cultura". (ECKERT-HOFF, 2008, p. 66). São as relações de poder que se fazem instaurar em determinados momentos da história, a partir dos acontecimentos, que determinam as possíveis (re)ações dos sujeitos.

Vale notar que, também, o discurso de SP2 traz a representação da L2 como mecanismo de controle, que agrega a questão da língua à sobrevivência da etnia. Para ele, a exemplo do discurso do professor Genésio, trazido por Nincao (2008), sendo a L2 a língua majoritária, somente conseguirão ser índios se a “dominarem”, como veremos a seguir na resposta de SP2 à questão "Professor, como você vê a relação dos Terena com a língua materna e a língua portuguesa?":

\begin{abstract}
SP2- [...] então a linguagem ela é muito importante... eu tenho que dominar a minha linguagem e também da sociedade... entendeu... [...] porque sem a linguagem da sociedade envolvente a gente também não consegue sobreviver... porque você tem que fazer documento... oficio pro prefeito... oficio pra secretaria da educação e vários outros... entendeu... eu acho assim que é: por isso que a gente tem que dominar... [...]
\end{abstract}

Há um diferencial no discurso de SP2 quanto à escolha lexical, ou seja, embora fale da língua, o sujeito usa o termo "linguagem" (como sinônimo); todavia, pela discursividade apresentada pelo sujeito-professor, as construções ideológicas trazidas por SP2 estão mais próximas da concepção de linguagem do que de língua, uma vez que o sujeito não discute apenas a estrutura da língua em si, mas como ele a torna "viva" na sua funcionalidade.

Ao observarmos a sequência discursiva eu tenho que dominar a minha linguagem e também da sociedade, a compreensão do outro, discutida por Bakhtin (2006), coaduna-se com o dizer de SP2, pois, para o sujeito, o domínio de si e do outro só ocorre por meio da linguagem. Constituído pelo discurso de poder, por meio da perífrase de modalidade deôntica tenho que dominar, FD comum nos discursos de luta pela conquista de territórios, de terras, esse dizer vem revelar, pela dispersão, a ideologia da qual é constituído o discurso de SP2: somente a L1 não completa a identidade do sujeito; ele necessita do outro, mesmo que seja estranho, para se constituir. O "domínio" da minha linguagem refere-se à L1, que, embora citada em 
primeiro plano, encontra-se no mesmo patamar que a L2 e outras línguas (possivelmente o inglês e o espanhol, porque ambas também estão contempladas no currículo escolar dos Terena), línguas também da sociedade. Esse posicionamento de SP2 remete-nos a um "gesto de interpretação": o sujeito passa por uma espécie de reinvenção do "eu", dentro dos valores da (pós)modernidade e, de repente, muitos dos valores nele arraigados - comuns a povos de culturas consideradas diaspóricas, segundo Bhabha (2010) - promovem situações de cisão, ora positivas, ora não, dependendo da perspectiva.

Levando em consideração a política linguística dos Terena e, por meio dela, as conjunturas de poder, o "desejo imposto" pelo sujeito a si mesmo - tenho que dominar a L2 -, torna-se nítido que ele sabe do poder que lhe confere o ser proficiente também na língua de prestígio, o que lhe é caro e desejável.

Desse modo, a justificativa plausível encontrada por SP2 para argumentar a sua posição de aceitação/necessidade de conviver com duas ou mais línguas pode ser observada em porque você tem que fazer documento... ofício pro prefeito... ofício pra secretaria da educação e vários outros. A ideologia constituída no sujeito-professor é a de que ele sabe que a sociedade dominante, referenciada pelas vozes inscritas em prefeito, Secretaria da Educação e vários outros, não é falante da língua Terena, porque ela é uma língua "particular", de um grupo minoritário, e quem tem de "aprender" a língua estranha, do branco, mas de prestígio, é quem deseja ser constituído por ela. Num contexto de bilinguismo diglóssico indígena, aprender a língua majoritária é realmente condição para continuar sendo índio. Essa conduta associa-se ao postulado de Foucault (1997) por meio de dois pensamentos linguisticamente distintos, mas que revelam e discutem a mesma ideologia de origem: a escrita como valor de verdade e o poder, mesmo na "subserviência".

$\mathrm{O}$ ato de fazer documento em L2 e ser compreendido pelas autoridades trazidas por SP2, que, de certo modo, detêm o poder, instaura, no sujeito-professor, o desejo de igualdade, possibilitado pelo domínio da L2, que é a língua da sociedade dominante. Há, nesse ato de fala e de escrita, a busca pela comprovação de uma verdade (que o indígena compreende a língua do outro - L2) e por assim ser, "permite" ser compreendido pelo outro/branco e "fazer ser ouvido" por este, como se demarcando pontos de poder do micro (Terena) sobre o macro (Branco), mas no desejo de misturarse a ele. Dessa maneira, nas palavras de Foucault (1992, p. 150), "escrever é, pois, 'mostrar-se', dar-se a viver, fazer aparecer o rosto próprio junto ao outro", mas como 
entidade de poder. Escrevem-se "escritas de poder" por intermédio do fazer documento das minorias às autoridades que têm o poder nas mãos. O domínio da L2, na ideologia de SP2, coloca-o como passível de mobilidade naquilo que o fortalece, ora como defesa, ora como sobrevivência: a língua.

Os equívocos e lapsos na sequência discursiva de SP2 podem ser observados de modo crescente, pois ao testificar a necessidade de aprender a L2, o sujeito não se restringe à comunicação cotidiana (banco, mercado, lojas), mas a instâncias de poder (prefeito, secretaria de educação), ou seja, mobiliza a aprendizagem da L2 como macro poder.

SP2, como sujeito do século XXI, representa o indivíduo que busca sobreviver (entendamos sobreviver como um ato amplo em que se conjugam vida e cultura) em meio às identidades fragmentadas, concebendo o outro, embora estranho, como constituinte de sua identidade, indivíduo definido por Eckert-Hoff (2008, p.40) como "um sujeito camaleônico", que, como camaleão, "muda constantemente de forma e de cor. Nessa metamorfose, ele não deixa de ser um para ser outro, pois um está constituído pelo/no outro, é sempre o mesmo no diferente e o diferente no mesmo".

A metamorfose dos sujeitos, num contexto de minoria linguística, representada pela escolha da proficiência na língua majoritária, marca a representação da língua, no caso, a L2, como mecanismo de controle, sujeitos compostos, conforme Bhabha (2010), marca latente de mobilidade dos mecanismos de controle. Coracini (2007, p. 61) argumenta que o "sujeito é, assim, fruto de múltiplas identificações - imaginárias e/ou simbólicas" que vão se entrelaçando e construindo por meio do inconsciente, a subjetividade. A autora afirma que a identidade só se torna possível pela ilusão de pertença a um determinado grupo, uma vez que o sujeito se constitui no/pelo olhar do outro que é semelhante e diferente de si mesmo, simultaneamente, afirmando uma identidade em oposição à outras pelas maneiras de se representar e apresentar o mundo à sua volta e que dá sentido às suas práticas sociais.

Em entrevista concedida ao jornalista italiano Benedetto Vecchi, Zygmunt Bauman (2005) faz diversas considerações sobre a questão da identidade, desde o momento em que as pessoas começaram a ter noção de suas próprias identidades até os dias atuais, quando a humanidade oscila entre diversas "identidades" que são impostas ou oferecidas. O autor afirma que questões acerca da identidade só surgem quando os indivíduos são expostos a "comunidades da segunda categoria" (BAUMAN, 2005, p. 17), quando são obrigados a absorver traços identitários que sejam adequados a essa 
situação ou quando são confrontados com uma possibilidade maior de comparações e escolhas que passam a "guiar" sua identidade. A coexistência do branco com o índio propiciou que este último pudesse observar e fazer suas escolhas no que se refere à questão identitária; antes dessa convivência, não havia essa possibilidade.

Embora haja a possibilidade de escolha de identidade para adaptação a determinadas comunidades, Bauman (2005, p. 18) considera que estar fora de seu local ou cultura de origem faz que o indivíduo seja considerado "deslocado" e cita, como exemplo, sua própria condição: polonês refugiado na Grã-Bretanha e perfeitamente ambientado nesse cenário, considerava-se um "estranho" dentro dele, embora também já não pudesse ser considerado polonês por ter sido privado de sua cidadania original. Sobre esse dilema, afirma: "As pessoas em busca de identidade se veem invariavelmente diante de uma tarefa intimidadora de 'alcançar o impossível"” (BAUMAN, 2005, p. 16). Essa condição reflete a já citada condição do índio na atualidade: não pode ser considerado completamente indígena, pois já não traz apenas sua cultura de origem, nem pode ser considerado completamente branco, pois ainda há em si marcas de sua cultura e etnia que não permitem essa completude.

\section{Palavras Finais}

Este trabalho teve como meta tecer reflexões sobre as representações de língua (Terena e Portuguesa) como mecanismos de defesa na relação com o branco, no bojo da sociedade hegemônica.

Pode-se afirmar que os discursos dos sujeitos das sequências discursivas, SP1 e SP2, se constituem por meio das formações discursivas que oscilam entre o passado e o presente, via memória discursiva, mas sob dois vieses: ora a L1 é representada como mecanismo de controle, ora a L2 é quem recebeu esse lugar, no entanto sempre perpassada pelas relações de poder, ao longo da história.

A representação da língua Terena como mecanismo de controle remete-nos ao aqui-agora, que pôde ser observado, sobretudo pela recorrência ao espelhamento da sociedade sobre a representação do que é ser "índio verdadeiro", que delega a este a incumbência de falar a língua indígena para que, somente "provando" a indianidade pela proficiência na L1, possa usufruir dos benefícios destinados apenas aos tutelados.

Esse mecanismo de controle vem permeado pelos discursos de defesa ao poder do branco por duas óticas: a aprendizagem da L2 e também da L1 simultaneamente, ou 
seja, a aprendizagem da L2 pela geração mais jovem seria a garantia de não se repetir a história dos antepassados, que, falando somente a L1, foram alvo de estereótipos e preconceitos sociais, dizimando os Terena no próprio território de reserva e da L1, como garantia da indianidade.

As assertivas sobre a aprendizagem da L2 são justificadas numa relação de poder do menor para o maior e consequentemente para o usufruto do mais-gozar. A ideologia que constitui a palavra estratégia (no discurso de SP1 e referenciada por SP2) condensa a política linguística dos Terena: falar a L2 para saber o que/como o branco pensa e poder traçar autodefesa de resguardo da etnia, para ocupar espaços que o branco ocupa, negados ao indígena, enfim: saber/poder falar a L2 como manifestação de poder.

Os discursos dos sujeitos, a todo o momento, foram revestidos de uma ideologia simultânea de mecanismos de defesa e de poder, reiterando a presença da metáfora do Narciso-Vampiro contemplada por Eckert-Hoff (2008), ou seja, ao mesmo tempo em os sujeitos buscavam a autocontemplação (a exemplo de Narciso) por meio do "julgar-se capaz" e com desejos de igualdade frente à sociedade hegemônica é corrompido e não pode realizar ação de autocontemplar-se (Vampiro) porque, externando suas novas identidades, a sociedade majoritária não aceitaria e colocaria em risco as conquistas étnicas já alcançadas.

O jogo duplo de subserviência do indígena em relação ao branco, de certo modo, coloca-os numa esfera estratégica a exemplo da teoria do camaleão também citada pela autora: a camuflagem do réptil é condição essencial para sua sobrevivência, fato que não se diverge do Terena, isto é, fazer o "jogo" da sociedade dominante reforça o meio estratégico de camuflagem que garante a continuidade da etnia.

É possível compreender que as representações trazidas nos discursos dos docentes (SP1 e SP2) reforçam a premissa de que o discurso desnuda-nos, exteriorizanos, e que a façanha ou ousadia em procurar analisá-los e tentar compreendê-los exige a observação de um atravessamento do discurso pelo acontecimento, ou seja, da história desse povo desde a Guerra do Paraguai ao momento da formação e atuação do docente indígena na educação.

Ademais, a duplicidade de defesa e de poder ficaram tão emaranhadas e tão interdependentes que não podemos afirmar ser um índio Terena imutável, com identidade fixa, e mais ainda, nem tampouco definida, o que pode ser muito bem explicado pela teoria do caleidoscópio de Cavalcanti e César (2007) pela multiplicidade de cores que o objeto revela conforme o movimento/mudança deste. A constituição do 
docente indígena, por meio do discurso, desvela e confunde, simultaneamente, qual representação identitária que ele prima em cada momento, portanto, não é uno e nem o mesmo.

Nessa visão discursiva, em que a descontinuidade está presente também na interpretação de textos decorrentes de gestos espontâneos de leitura, as identidades se definem como movimento na língua [Terena/Portuguesa] e na história, por meio de marcas de resistência e de poder, que se mostram no discurso, e não são apenas representativas de uma modalidade de língua: são marcas históricas, por isso assinalam o movimento de constituição da identidade do índio e do seu discurso.

Nesse sentido, confirmamos, ainda que parcialmente, tendo em vista os dois recortes examinados, nossa hipótese de que os professores indígenas Terena da Região de Aquidauana (MS) têm alteradas as suas formações discursivas e suas ideologias, bem como as suas identidades docentes a partir de suas relações com a sociedade dominante como efeito de espelhamento. Aguardamos outras pesquisas que lancem mais luzes a essas questões que nos instigam e nos mobilizam...

\section{Referências}

BAKHTIN, Mikhail (Volochínov). 2006. Marxismo e filosofia da linguagem. 12. ed. Trad. Michel Lahud e Yara Frateschi Vieira. São Paulo: Hucitec.

BAUMAN, Zygmunt. Identidade. 2005. Entrevista a Benedetto Vecchi. Trad. de Carlos Alberto Medeiros. Rio de Janeiro: Zahar.

BHABHA, Hommi. 2010. O local da cultura. 5. ed. Trad. Miriam Ávila, Eliana L. Reis e Gláucia R. Gonçalves. Belo Horizonte: Editora UFMG.

BRASIL. Ministério da Educação e do Desporto. 1999. Referencial Curricular nacional para as Escolas Indígenas. Brasília: MEC/Secretaria de Educação Fundamental.

CARDOSO, Silvia H. B. 1999. Discurso e Ensino. Belo Horizonte: Autêntica.

CAVALCANTI, Marilda C; CÉSAR América L. Do singular para o multifacetado: o conceito de língua como caleidoscópio. 2007. In: CAVALCANTI, Marilda C, BORTONI-RICARDO, Stella M. (Orgs). Transculturalidade, linguagem e educação. Campinas: Mercado das Letras. p. 45-66.

CORACINI, Maria J. R. F. 2007. A celebração do outro. Arquivo, memória e identidade. Campinas: Mercado de Letras. 
2003. Identidade e discurso: (des)construindo subjetividades. Campinas: Editora da Unicamp; Chapecó: Argos Universitária.

ECKERT-HOFF, Beatriz M. 2008. Escritura de si e identidade: o sujeito-professor em formação. Campinas: Mercado de Letras.

FOUCAULT, Michel. Method. In: The History of Sexuality. Cap II, Volume

I. Translated by Robert Hurley, New York: Vintage Books, 1990, p. 92-102, [1976]. 129-160.

A escrita de si. 1992. In: O que é um autor? Lisboa: Passagens. p.

A microfísica do poder. 1997 [1979]. In: A vontade de saber. 12 ed. Trad. de M. T. Albuquerque. Rio de Janeiro: Graal.

. Arqueologia do saber. 1987 [1969]. 3 ed. Trad. de Baeta Neves. Rio de Janeiro: Forense Universitária.

GUERRA, Vânia M. L. 2010. O indígena de Mato Grosso do Sul: práticas identitárias e culturais. São Carlos: Pedro \& João Editores.

LADEIRA, Maria I.; AZANHA, Gilberto E. Cosmologia e Xamanismo, 2004. Disponível em: 〈http://pib.socioambiental.org/pt/povo/terena/1045> Acesso em 26 de fevereiro de 2012, às $15 \mathrm{~h} 33 \mathrm{~min}$.

MAHER, Tereza M. Sendo Índio em português... 4 ed. 2006. In: SIGNORINI, I. (Org.). Lingua(gem) e identidade. Campinas: Mercado das Letras, p. 115-138.

MARIANI, Bethania. 2004. Colonização lingüística. Campinas: Pontes.

NINCAO, Onilda S. 2008. "Kóho Yoko Hovôvo/ O Tuiuiú e o Sapo": identidade, biletramento e política linguística na formação continuada de professores Terena. Campinas: Universidade Estadual de Campinas. (Tese de doutoramento).

OLIVEIRA, Roberto. C. de. 1976. Do índio ao bugre; o processo de assimilação dos Terêna. Rio de Janeiro: Livraria Francisco Alves.

ORLANDI, Eni P. 2002. Língua e conhecimento linguístico: Para uma história das ideias no Brasil. São Paulo: Cortez.

2009. Análise de discurso: princípios e procedimentos. 8 ed. Campinas: Pontes.

PRETI, Dino. 2001 Apresentação. In: PRETI, Dino (Org.). Análise de textos orais. Projetos Paralelos - NURC/SP, 5.ed. São Paulo: Humanitas, p.11-12. 


\section{Para citar essa obra:}

PORTO, Alessandra Manoel; GUERRA, Vânia Maria Lescano. Subjetividade e discurso: a representação da língua (indígena e portuguesa) para professores Terena. RUA [online]. 2013, no. 19. Volume 1 - ISSN 1413-2109

Consultada no Portal Labeurb - Revista do Laboratório de Estudos Urbanos do Núcleo de Desenvolvimento da Criatividade

http://www.labeurb.unicamp.br/rua/

Capa: CAMPANATO. Valter; BRASIL, Agência. 2007. Disponível em:

http://pt.wikipedia.org/wiki/Ficheiro:Menina da etnia Terena.jpg

\section{Laboratório de Estudos Urbanos - LABEURB}

Núcleo de Desenvolvimento da Criatividade - NUDECRI

Universidade Estadual de Campinas - UNICAMP

http://www.labeurb.unicamp.br/

Endereço:

LABEURB - LABORATÓRIO DE ESTUDOS URBANOS

UNICAMP/COCEN / NUDECRI

CAIXA POSTAL 6166

Campinas/SP - Brasil

CEP 13083-892

Fone/ Fax: (19) 3521-7900

Contato: http://www.labeurb.unicamp.br/contato 